\title{
DMTA Analysis of Glycerol Diglycidyl Ether Based Photocross-linked Polymers
}

\author{
Sigita Kasetaite $^{1}$, Jolita Ostrauskaite ${ }^{1}$, Violeta Grazuleviciene ${ }^{2}$ \\ ${ }^{1}$ Department of Polymer Chemistry and Technology, Kaunas University of Technology \\ Radvilenu rd. 19, LT-50254 Kaunas, Lithuania \\ sigita.kasetaite@ktu.lt; jolita.ostrauskaite@ktu.lt \\ ${ }^{2}$ Department of Chemistry, Aleksandras Stulginskis University \\ Studentu str. 11, LT-53361 Akademija, Kaunas distr., Lithuania \\ violeta.grazuleviciene@asu.It
}

\begin{abstract}
In this paper, the effect of the amount and chemical structure of the structurally different alcohols on the rheological properties of the photocross-linked glycerol diglycidyl ether based polymers was investigated by dynamic-mechanical thermal analysis. The glass transition temperatures of photocross-linked polymers were determined from the onset point of storage modulus G' curve, maximum peak of loss modulus G" curve and the maximum peak of the loss factor tan $\delta$ curve. The lower concentration of alcohol was used in the batch the higher glass transition temperature and the increased height of the storage modulus G' curve was obtained as a consequence of the formed more rigid structure of polymers.
\end{abstract}

Keywords: photocross-linking, glass transition, dynamic-mechanical thermal analysis

\section{Introduction}

The glass transition temperature $\left(\mathrm{T}_{\mathrm{g}}\right)$ is a key characteristic of plastics and often defines the temperature range in which the plastics may be used because it is a temperature at which material undergoes the transformation from rubbery to glassy state. The $\mathrm{T}_{\mathrm{g}}$ is one of the most important and representative parameters of the chemical and physical properties of polymers [1,2]. In the highly viscous region above the $T_{g}$, polymeric materials are soft and rubbery, and below the $T_{g}$, polymers are hard and brittle [3]. In general, transitions in materials are associated with different localized or medium-to long-range cooperative motions of molecular segments. The glass transition is associated with cooperative motion among a large number of chain segments, including those from neighboring polymer chains [4]. When polymer chains are linked together by cross-links, they lose some of their ability to move. Cross-linking of polymers tends to increase $\mathrm{T}_{\mathrm{g}}$ also increase rigidity [5].

Although there are several techniques available to make $T_{g}$ measurements, by far the most sensitive and most used technique is dynamic-mechanical thermal analysis (DMTA). This method is relatively rapid and particularly suitable for quality control applications [6]. DMTA gives a number of measures of the glass transition temperature [7]. The onset point of the storage modulus $\mathrm{G}^{\prime}$ as a function of temperature is the midpoint between the glassy and rubbery regions, and as such, is a measure of $\mathrm{T}_{\mathrm{g}}$. It occurs at the lowest temperature and relates to mechanical failure. The temperature at which the maximum peak of the loss modulus G" curve appears is often used as well. The G" modulus maximum peak occurs at the middle temperature and is more closely related to the physical property changes attributed to the glass transition in plastics. It reflects molecular processes and agrees with the idea of $\mathrm{T}_{\mathrm{g}}$ as the temperature at the onset of segmental motion. The loss factor $\tan \delta$ is the ratio of the loss modulus and the storage modulus. The temperature at which the tan $\delta$ maximum peak occurs is also a measure of the glass transition temperature, but is generally $10{ }^{\circ} \mathrm{C}$ or more higher than the loss modulus maximum peak or storage modulus onset point. The height and shape of the tan $\delta$ peak change systematically with amorphous content [4].

In this study, four structurally different alcohols were chosen for the investigation of the effect of their chemical structure and amount on the glass transition temperature and reological properties of the resulting photocross-linked polymers. 


\section{Experimental}

\subsection{Polymer preparation}

The different compositions (C1-C12, see Table 1) were prepared by mixing of $0.2 \mathrm{~g}(0.98 \mathrm{mmol})$ glycerol diglycidyl ether with the different amounts $(10,20$, or $30 \mathrm{~mol} . \%)$ of structurally different alcohols, 1,4-cyclohexanedimethanol (1), 1,1,1-tris(hydroxymethyl)propane (2), hydroquinone (3), bisphenol A (4), using $3 \mathrm{~mol} \%$ of photoinitiator, mixture of triarylsulfonium hexafluoroantimonate salts, and $0.1 \mathrm{ml}$ of tetrahydrofuran. The composition without any alcohol (C0) was prepared for comparison. The components were stirred vigorously with a magnetic stirrer, poured on a plastic film, and kept at the room temperature under the Helios Italquartz UV lamp (model GR.E $500 \mathrm{~W}$ ) with UV light intensity of $310 \mathrm{~mW} \cdot \mathrm{cm}^{-}$

2 at the distance of $15 \mathrm{~cm}$ until the hard film was obtained (after (2-4) min). The thickness of the photocross-linked polymer films was $0.2 \mathrm{~mm}$.

\subsection{Dynamic-mechanical thermal testing}

DMTA was performed in torsion mode using MCR302 rheometer from Anton Paar equipped with the plate/plate measuring system. The temperature was raised from $-20^{\circ} \mathrm{C}$ to $45^{\circ} \mathrm{C}$ at a heating rate of $2{ }^{\circ} \mathrm{C} / \mathrm{min}$. The frequency of $1 \mathrm{~Hz}$ and the strain of $0.5 \%$ was used in all cases. The $\mathrm{T}_{\mathrm{g}}$ was defined by the onset point of the storage modulus $\mathrm{G}^{\prime}$ curve, the maximum peak of the loss modulus $\mathrm{G}^{\prime \prime}$ curve and the maximum peak of the loss factor $\tan \delta$ curve.

\section{Results and discussion}

The photocross-linking of the batches prepared from glycerol diglycidyl ether and structurally different alcohols resulted in the transparent polymer films. The $\mathrm{T}_{\mathrm{g}}$ values of the photocross-linked polymers obtained from the batches $\mathbf{C 0}$ C12 are presented in Table 1.

Table 1: Glass transition temperatures of the polymers obtained from the batches $\mathrm{C} 0-\mathrm{C} 12$.

\begin{tabular}{|c|c|c|c|c|c|}
\hline Batch & Alcohol & $\begin{array}{c}\text { Concentration } \\
\text { of alcohol, mol.\% }\end{array}$ & $\mathbf{T}_{\mathrm{g}}{ }^{\mathbf{a}},{ }^{\mathbf{o}} \mathbf{C}$ & $\mathbf{T}_{\mathrm{g}}{ }^{\mathbf{b}},{ }^{\mathbf{o}} \mathrm{C}$ & $\mathbf{T}_{\mathrm{g}} \mathbf{c},{ }^{\mathbf{o}} \mathrm{C}$ \\
\hline C0 & - & - & 5 & 8 & 13 \\
\hline C1 & \multirow{3}{*}{1} & 10 & -1 & 2 & 11 \\
\hline $\mathrm{C2}$ & & 20 & -2 & 1 & 8 \\
\hline $\mathrm{C3}$ & & 30 & -3 & 0 & 7 \\
\hline C4 & \multirow{3}{*}{2} & 10 & $\begin{array}{l}-1 \\
\end{array}$ & 3 & 10 \\
\hline $\mathrm{C5}$ & & 20 & -4 & -2 & 5 \\
\hline C6 & & 30 & -8 & -6 & 0 \\
\hline C7 & \multirow{3}{*}{3} & 10 & 9 & 11 & 18 \\
\hline C8 & & 20 & 8 & 10 & 16 \\
\hline C9 & & 30 & 2 & 5 & 12 \\
\hline C10 & \multirow{3}{*}{4} & 10 & 9 & 12 & 18 \\
\hline C11 & & 20 & 8 & 11 & 17 \\
\hline C12 & & 30 & 6 & 9 & 15 \\
\hline
\end{tabular}

a - Glass transition temperature from the onset point of the storage modulus G' curve;

b - Glass transition temperature from the maximum peak of the loss modulus G" curve;

${ }^{\mathrm{c}}$ - Glass transition temperature from the maximum peak of.the loss factor tan $\delta$ curve.

The DMTA data confirmed that the photocross-linked polymers obtained from the batches C0-C12 are amorphous materials. Only the glass transitions were observed in the DMTA curves of all the polymers prepared. The $\mathrm{T}_{\mathrm{g}}$ 's of polymers obtained from the batches $\mathbf{C 0}-\mathbf{C 1 2}$ recorded from the onset point of the storage modulus G' curves appeared at the lowest temperature (from $-8{ }^{\circ} \mathrm{C}$ to $9{ }^{\circ} \mathrm{C}$ ), the $\mathrm{T}_{\mathrm{g}}$ 's registered from the maximum peak of the loss modulus $\mathrm{G}^{\prime \prime}$ curves appeared at the middle temperature (from $-6{ }^{\circ} \mathrm{C}$ to $12{ }^{\circ} \mathrm{C}$ ) and the $\mathrm{T}_{\mathrm{g}}$ 's recorded from the maximum peak of the tan $\delta$ curves appeared at the highest temperature (from $0{ }^{\circ} \mathrm{C}$ to $18{ }^{\circ} \mathrm{C}$ ). The $\mathrm{T}_{\mathrm{g}}$ values of the polymers obtained from the batches C7-C9 with the aromatic alcohol 3, as well as of the polymers obtained from the batches 
C10-C12 with the aromatic alcohol 4 were higher than those of the polymers obtained from the batches C1-C3 and C4-C6 with the fragments of the aliphatic alcohols $\mathbf{1}$ and $\mathbf{2}$ due to the lower chain mobility caused by the steric hindrance of the aromatic fragments of the alcohols $\mathbf{3 , 4}$ molecules [8]. The $\mathrm{T}_{\mathrm{g}}$ values of the polymers obtained from the batches C4-C6 with aliphatic alcohol $\mathbf{2}$ with three hydroxyl groups were lower than those of the polymers obtained from the batches C1C3 with the fragments of the aliphatic alcohol 1 with two hydroxyl groups due to proton-trapping effect. The $T_{g}$ values of the polymers obtained from the batches C10-C12 with more aromatic fragments were higher than the polymers obtained from the batches $\mathbf{C 7}$-C9 due to more rigid macromolecular chains.

The storage modulus G' curves of the polymers obtained from the batches C10-C12 with different concentrations (10, 20, $30 \mathrm{~mol} . \%$ ) of the alcohol $\mathbf{4}$ are presented in the Figure 1.

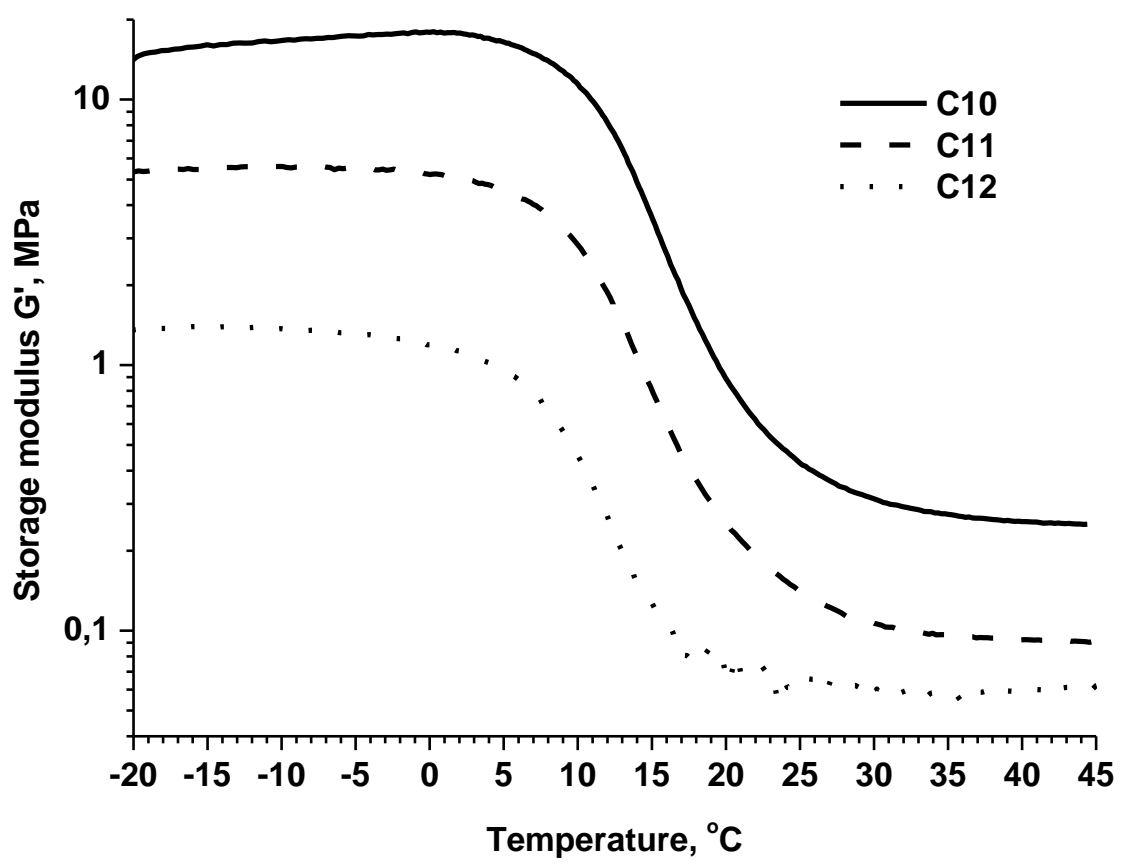

Fig. 1: Storage modulus curves of the polymers obtained from the batches C10-C12 with different concentrations (10, 20, 30 mol.\%) of the alcohol 4.

The lower concentration of alcohol was used, the higher $\mathrm{T}_{\mathrm{g}}$ value was observed and the height of the storage modulus curve was increased. The last observation suggests that the large number of protons released are trapped by alcohol molecules, and can not continue the chain growth reaction, resulting in a decreased $\mathrm{T}_{\mathrm{g}}$ value [8]. As a result of this, the more rigid structures of polymers were formed when the lower amounts of alcohol were used in the batch.

The DMTA curves of the polymer obtained from the batch $\mathbf{C 1}$ with $10 \mathrm{~mol} \%$ concentration of the alcohol $\mathbf{1}$ as a function of temperature are presented in Figure 2. 


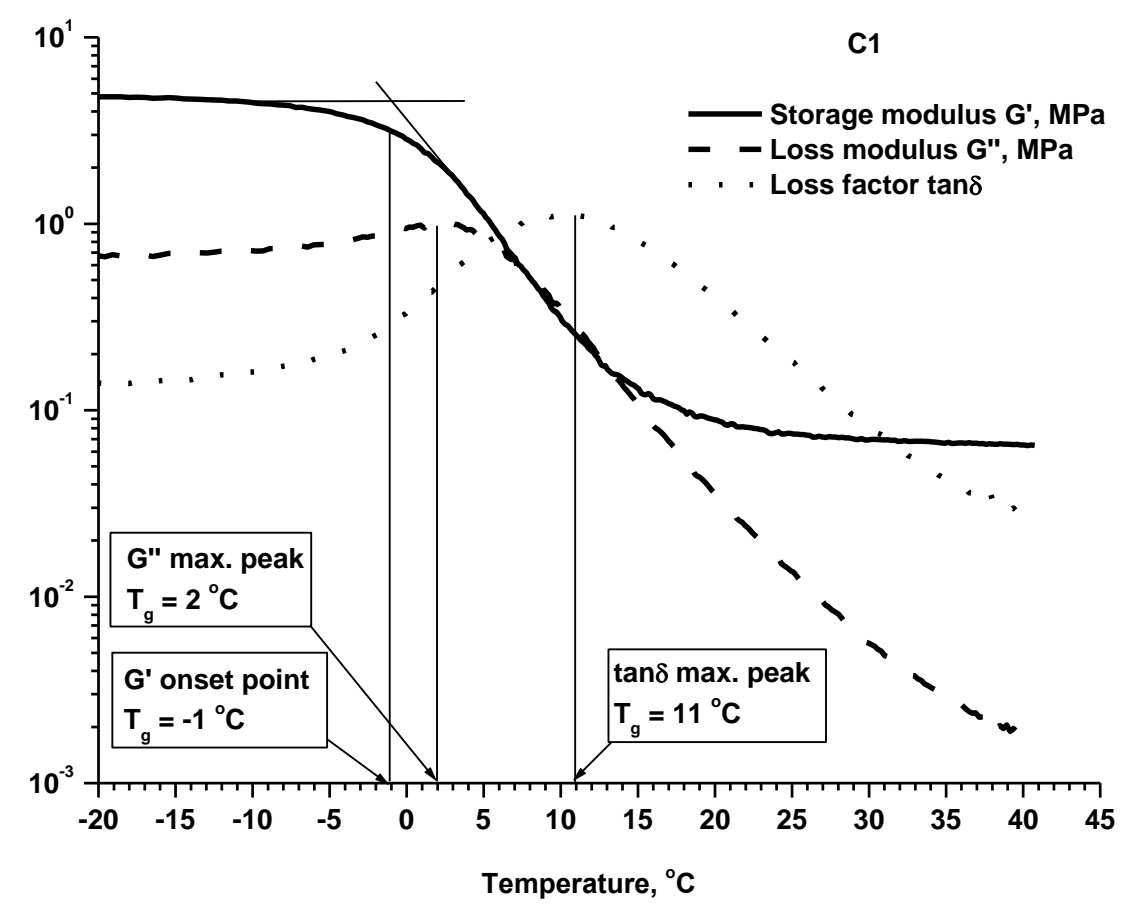

Fig. 2: DMTA curves of the polymer obtained from the batch $\mathbf{C 1}$ with 10 mol.\% concentration of the alcohol $\mathbf{1}$.

At low temperatures (from $-20{ }^{\circ} \mathrm{C}$ to $-1{ }^{\circ} \mathrm{C}$ ), the molecules are motionless and are unable to resonate with the oscillatory loads and remain rigid. The rigidity of thermosetting resin is indicated by the storage modulus [9]. The polymer is in the glass state or energy elastic state at the low temperatures. The macromolecular segments can not change shape, especially through rotation about $\mathrm{C}-\mathrm{C}$ bonds, and so the molecular entanglements act as rigid cross-links. Storage modulus decreases as the molecules gain more free volume resulting in more molecular motions when temperature increases [10]. The glass state changes into the rubber-elastic state. The step of the storage modulus directly preceding the drop corresponds to the $\mathrm{T}_{\mathrm{g}}=-1{ }^{\circ} \mathrm{C}$ (Fig. 1). The loss modulus, which is a measure of the dissipated energy, reaches the maximum at $2{ }^{\circ} \mathrm{C}$ (Fig. 1). The definition of the $\mathrm{T}_{\mathrm{g}}$ as the temperature at which tan $\delta$ reaches the maximum is the most frequently cited in the literature, because the $\tan \delta$ curves with the maximum peak are easier to evaluate than the step curves. The loss factor $\tan \delta$ curve of the polymer obtained from the batch $\mathbf{C 1}$ reached maximum peak at $\mathrm{T}_{\mathrm{g}}=11^{\circ} \mathrm{C}(\mathrm{Fig} .1)$. The polymer transits to the rubber state (from $11{ }^{\circ} \mathrm{C}$ to $45^{\circ} \mathrm{C}$ ). The DMTA curves of the other photocross-linked polymers were in the same character (storage modulus $\mathrm{G}^{\prime}$ onset point occured at the lowest temperature, loss modulus $\mathrm{G}^{\prime \prime}$ maximum peak occured at the middle temperature and finally the loss factor $\tan \delta$ maximum peak appeared).

\section{Conclusion}

The dynamic-mechanical thermal analysis indicated that the reological properties of the photocross-linked polymers of glycerol diglycidyl ether and the structurally different alcohols were affected by chemical structure and amount of the used alcohol. The structural characteristics of the different alcohol molecules, e. g. steric hindrance and proton-trapping effect determine the glass transition temperature of the photocross-linked polymers of glycerol diglycidyl ether and structurally different alcohols. The higher concentration of alcohol was used in the batch the lower glass transition temperature of the resulting polymer was obtained due to the association with the proton. The amount of alcohol had the crucial influence on the reological properties of the obtained photocross-linked polymers.

\section{Acknowledgements}

This work was supported by the Research Council of Lithuania (project No. MIP-066/2015). 


\section{References}

[1] S. Lu, D. Chen, X. Wang, X. Xiong, K. Ma, L.Zhang, Q. Meng, "Monitoring the glass transition temperature of polymeric composites with carbon nanotube buckypaper sensor," Polym. Test., vol. 57, pp. 12-16, 2017.

[2] R. J., Young, P. A. Lovell, Introduction to polymers. Boca Raton, FL, CRC Press, 2011.

[3] J. Rieger, "The glass transition temperature $\mathrm{T}_{\mathrm{g}}$ of polymers-comparison of the values from differential thermal analysis (DTA, DSC) and dynamic mechanical measurements (torsion pendulum)," Polym. Test., vol. 20, pp. 199$204,2001$.

[4] E. A. Turi, Thermal Characterization of Polymeric Materials. Brooklyn, New York: Academic Press, 1997.

[5] J. T. Morisette, M. D. Schwartz, C. M. Hogan, Phenology. In: The Encyclopedia of Earth. Washington: D. C., 2011.

[6] G. Bussu, A. Lazzeri, "On the use of dynamic mechanical thermal analysis (DMTA) for measuring glass transition temperature of polymer matrix fibre reinforced composites," J. Mater. Sci., vol. 41, pp. 6072-6076, 2006.

[7] J. La Scala, R. P.Wool, "Fundamental thermo-mechanical property modeling of triglyceride-based thermosetting resins," J. Appl. Polym. Sci., vol. 127, pp. 1455-2361, 2013.

[8] Z. Wang, X. Lin, W. Liu, "Synthesis of bis(2,3-epoxycyclohexyl) and its cationic photopolymerization in the presence of different diols," Polym. Int., vol. 58, pp. 74-80, 2009.

[9] Z. Candan, D. J. Gardner, S. M. Shaler, "Dynamic mechanical thermal analysis (DMTA) of cellulose nanofibril/ nanoclay/pMDI nanocomposites," Composites Part B, vol. 90, pp. 126-132, 2016.

[10] S. K. Kemei, M. S. K. Kirui, F. G. Ndiritu, P. M. Odhiambo, R. G. Ngumbu, D. M. G. Leite, A. L. J. Pereira, "Storage moduli, loss moduli and damping factor of GaAs and $\mathrm{Ga}_{1 \_\mathrm{x}} \mathrm{Mn}_{\mathrm{x}} \mathrm{As}$ thin films using DMA 2980," Mater. Sci. Semicond. Process., vol. 20, pp. 23-26, 2014. 